\title{
BEBÊS COM RISCO DE AUTISMO: O NÃO-OLHAR DO MÉDICO*
}

Mariana Rodrigues Flores e Luciane Najar Smeha

Mariana Rodrigues Flores

Psicóloga, mestre

em Distúrbios

da Comunicação

Humana pela

Universidade

Federal de Santa

Maria (UFSM) e

especialista em

Clínica Psicanalítica

(Ulbra/SM), Santa

Maria/RS.

Luciane Najar Smeha Psicóloga, doutora em Psicologia (PUCRS), professora orientadora do Centro Universitário Franciscano (Unifra), Santa Maria/RS.

RESUMO: Abordamos aqui a possibilidade de detecção do risco e da intervenção precoce do autismo na visão dos médicos. A análise dos resultados de uma pesquisa feita em 2009 com sete pediatras e três neuropediatras de uma cidade da região central do Rio Grande do Sul, utilizando a análise de conteúdo de Bardin (1977) relacionada à Psicanálise, aponta que os diagnósticos de autismo são feitos tardiamente. Os profissionais não estão preparados para a detecção dos sinais de risco, o que não possibilita a intervenção precoce. É necessário, portanto, trabalhar com esses profissionais para indicar-lhes os sinais de risco de autismo.

Palavras-chave: Médicos, autismo, risco, intervenção precoce.

ABSTRACT: Babies in risk of autism: the non-looking of a doctor. In this study, it is approached the possibility of risk detection and early autism intervention by medical view. Thus, it's showed the results of a research made with seven pediatrician and three neuropediatricians from a central city in Rio Grande do Sul, in 2009, using the content analysis based on Bardin (1997) and related to psychoanalyses. The results pointed that the diagnosis of autism are made late, also the professionals involved are not able to detected the risk signs and this doesn't make early intervention possible. Therefore, it's necessary to work with these professionals to alert them about the risk signs of autism.

Keywords: Doctors, autism, risk, early intervention.

* Trabalho final de graduação do curso de Psicologia do Centro Universitário Franciscano (Unifra). 


\section{INTRODUÇÃO}

Apresentamos aqui os resultados de uma pesquisa, feita em 2009, com pediatras e neuropediatras de uma cidade da região central do Rio Grande do Sul sobre o autismo, enfocando as possibilidades de detecção do risco e intervenção precoce. Para tanto, realizamos uma discussão com abordagem psicanalítica.

Nessa perspectiva muitos estudos vêm sendo realizados de modo a que sejam validados os indicadores clínicos para o risco psíquico que inclui o autismo. Ademais, estes estudos apontam que, quanto mais precoce a intervenção, melhores serão os resultados obtidos. Correia (1997), em sua prática, observou que seu trabalho sofre alterações de acordo com a idade da criança — quanto mais cedo se fizer o diagnóstico, maiores as chances de uma evolução favorável. Ressaltou também que desde muito cedo algumas mães já relatam um "estranhamento" em relação ao bebê, o que possibilitaria a detecção de riscos de possíveis distúrbios psíquicos por meio de uma anamnese com os pais.

A psicanálise tem trabalhado com o risco de autismo, já que pressupõe que a criança não nasce sujeito, mas a subjetividade nela se instala pelo discurso familiar, o qual se refere ao desejo materno e à lei paterna (INFANTE, 2000). A constituição psíquica do bebê é estruturada por três tempos pulsionais: o primeiro tempo é ativo (o bebê vai em direção a um objeto externo); o segundo é reflexivo (o bebê toma seu corpo como objeto); e o terceiro, por fim, é eminentemente ativo (o bebê se faz objeto de outro). Acredita-se que, no autismo, há uma falha nesse terceiro tempo do circuito pulsional (LAZNIK, 2004).

A mãe sustenta para seu bebê o lugar de Outro primordial, pois, movida pelo desejo, antecipará em seu bebê uma existência subjetiva, que ainda não se constituiu, mas que se irá instalar justamente por esta suposição materna. A mãe desenhará, com pequenos e imperceptíveis reconhecimentos recíprocos, o mapa libidinal de seu bebê por meio de seu olhar, seu gesto e sua voz. O bebê responde aos investimentos da mãe, seja na busca do rosto materno, seja no seu sorriso. Quando esses atos de reconhecimento recíproco começam a falhar, é possível perceber, já por volta dos seis meses de vida, os primeiros traços autistas: a evitação do olhar humano, as hipotonias, a boca não erotizada, que baba constantemente, etc. (KUPFER, 2000).

Apesar disso, as razões para o fracasso do Outro não podem ser entendidas como ações volitivas e conscientes. Isso só tornaria os pais culpados e iria dificultar o seu papel nos cuidados do bebê, além de não contribuir para o tratamento. A justificativa dessa ideia é que o desempenho parental está relacionado à história pessoal de cada um, à história gestacional da criança e às condições do nascimento (WAJNTAL, 2000).

No Congresso Mundial de Autismo de 2005, em São Paulo, Laznik mencionou que é possível diagnosticar efetivamente o autismo apenas a partir dos 3 anos 
de idade — antes disso, pode-se perceber se há riscos de autismo. Entretanto, uma vez apontado esse risco, deve-se propor uma intervenção para que se possa atingir bons resultados, pois, mesmo que a criança não seja autista, apresenta um laço frágil com a figura maternante (CAMPANÁRIO, 2008). Por isso, é importante que o psicólogo trabalhe com o pediatra, já que este se dedica aos cuidados do bebê e pode auxiliar na detecção de risco precoce, possibilitando uma nova oportunidade para a criança e seus pais.

Dessa forma, na pesquisa, procuramos compreender como os pediatras e neuropediatras de uma cidade da região central do Rio Grande do Sul notam o autismo e seus sinais precoces. Além disso, há propostas de elucidar o conhecimento dos médicos sobre os sinais precoces de autismo; de compreender as possíveis intervenções realizadas por eles, quando identificam sinais prematuros ou diagnosticam o autismo em crianças; descrever a proposta da teoria psicanalítica quanto às possibilidades de intervenção antecipada diante do risco de autismo, bem como discutir os benefícios e malefícios da intervenção precoce em bebês.

\section{MÉTODO}

Utilizamos, nesta pequisa, a abordagem qualitativa, caracterizada por Richardson (1999) como a compreensão mais detalhada dos significados e características situacionais apresentados pelos participantes. Além disso, para Fraser e Gondim (2004), a abordagem qualitativa ou idiográfica pressupõe que a ação humana tem sempre um significado (subjetivo ou intersubjetivo) que não pode ser apreendido somente do ponto de vista quantitativo e objetivo.

O instrumento utilizado para a coleta de dados foi uma entrevista semiestruturada, aplicada individualmente nos consultórios dos profissionais e gravada em áudio, com autorização dos participantes e o compromisso de se manter sigilo sobre as identidades. As entrevistas duraram entre 10 minutos e uma hora. A escolha do tipo de entrevista baseou-se no nível de diretividade que os pesquisadores pretenderam seguir, além de ser uma abordagem que almeja compreender uma realidade particular e assumir forte compromisso com a transformação social por meio da autorreflexão e da ação emancipatória que pretende desencadear nos participantes da pesquisa (FRASER \& GONDIM, 2004).

Assim, foram convidados a participar da pesquisa 20 médicos, sendo quatro neuropediatras e 16 pediatras. No entanto, dez profissionais não aceitaram participar da pesquisa, alegando, em sua maioria, o não conhecimento da temática. A maior parte dos médicos, inclusive, pediu o roteiro das questões previamente. A pesquisa foi aprovada pelo Comitê de Ética do Centro Universitário Franciscano, segundo o registro 065.2009.3. Antes de cada entrevista, os participantes 
receberam o Termo de Consentimento Livre e Esclarecido que os deixava livres para participar ou não da pesquisa, como também para dela desistir a qualquer momento. No total, foram entrevistados três neuropediatras (NP) - embora um ainda esteja concluindo a formação - e sete pediatras (P). Para ambos os grupos, seguimos a ordem em que foram entrevistados.

O material foi transcrito e analisado conforme as diretrizes de Bardin. O método de Análise de Conteúdo é entendido como um conjunto de técnicas para análise das comunicações por meio de procedimentos sistemáticos e objetivos de descrição do conteúdo das mensagens, buscando obter indicadores quantitativos ou qualitativos. É uma técnica de tratamento e análise de informações, obtidas por meio da coleta de dados, consubstanciadas em um documento, objetivando-se compreender, criticamente, o sentido das comunicações em seu conteúdo manifesto ou latente (BARDIN, 1977).

Como resultado de análise, obtivemos cinco categorias: a formação profissional do médico no contexto do autismo; percepção dos médicos acerca do autismo, enquanto etiologia e características; diagnóstico; prognóstico e tratamento; e percepção dos sinais de risco.

\section{A FORMAÇÃO PROFISSIONAL DO MÉDICO NO CONTEXTO DO AUTISMO}

No século XIX surgiu a política higienista, produzida pela ordem médica, que ensinava os pais a cuidarem de seus filhos, revelando-lhes as deficiências e incompetências de seus cuidados. O pai passou a não exercer poder de vida e morte sobre os filhos, e esse foi o momento em que as mães se tornaram cuidadoras. Além disso, diferentemente dos tempos coloniais, concretizou-se o amor entre pais e filhos (COSTA, 1999).

Nesse viés, o saber médico tem papel importante no surgimento da infância, pois, além de buscar a prevenção de graves problemas que levavam as crianças à morte, possibilitou aos pais investirem nos filhos, que já não morriam tão precocemente. Apesar da preocupação dos médicos com os cuidados da infância, o que fez com que surgisse a pediatria, percebeu-se um grande déficit na formação acadêmica atual sobre os cuidados psíquicos da criança, em especial com relação ao autismo: “É, não faço ideia porque não tenho muita formação" (P 4); "Olha meu treinamento, eu não fui treinado para isso" (P 10).

Zanolli e Merhy (2001) constatam que o currículo das escolas médicas e suas reformulações acabam sendo superficiais porque, muitas vezes, voltam-se apenas para o atendimento das demandas do mercado profissional. Desse modo, para Degenszajn (2008), a construção de uma prática pediátrica que se preocupe com a singularidade do sujeito e considere os âmbitos sociais, culturais e psicológicos é um grande desafio para o ensino dessa categoria. 
Assim, na pesquisa, apontamos que esse déficit na formação dos pediatras faz com que estes não se responsabilizem pela clínica do autismo: "Acho que tem que lidar com uma pessoa especializada, né [sic], porque... com quem não entende não adianta... o pediatra, por exemplo, não sabe manejar" (P 4); "Não, estudei... cada um se detinha mais na parte que tinha mais interesse” (P 1).

É por isso que Bernardino (2008) afirma ser de extrema importância, no momento da avaliação, no consultório pediátrico ou até em creches que atendam a bebês, um olhar mais atento aos processos psíquicos, uma vez que são eles que permitem diferenciar o elemento realmente humano de uma aparelhagem biológica.

Todavia, neste estudo, revelou-se uma significativa diferença entre pediatras e neuropediatras no que se refere ao conhecimento acerca do autismo: os últimos mostram-se mais comprometidos com essa clínica e com maior conhecimento sobre o tema, independente da sua formação acadêmica, o que pode ser percebido a seguir: "Na minha formação especificamente não... De lá para cá... venho esses 35 anos estudando o tempo inteiro, eu vou acompanhando todas as mudanças" (NP 8).

Essa diferença entre pediatras e neuropediatras pode ser explicada pelos seus próprios perfis profissionais: a pediatria busca a prevenção ou a cura, enquanto a neuropediatria trabalha com os déficits mais complexos do desenvolvimento - portanto, lidar com o que não é passível de cura é algo que faz parte de sua rotina profissional. Assim, mesmo que a maioria dos pediatras atribua seu despreparo ao déficit na formação, faz-se necessário refletir sobre a própria origem da Medicina, pois esta se propõe a curar — mas em casos de autismo, pode-se falar de cura?

Em vários relatos, pode-se perceber a inquietação dos médicos que atendem a autistas por compreenderem o autismo como uma "doença crônica" (P 2), em que "não há muito o que se fazer" (P 9) ou "o tratamento do autista é frustrante" (NP 7). Sem dúvida, esses profissionais sentem-se impotentes diante de uma patologia supostamente incurável, mas isso vai de encontro aos princípios curativos da Medicina. Desse modo, a maioria se omite diante do desconhecimento e do que não é possível curar, pois ignora outras formas de ajudar o paciente autista e sua família. Pereira (2006) relata que, devido ao fato de a pediatria ter surgido para combater a mortalidade infantil, os pediatras tomam para si o papel de protetores da vida, portadores de um saber capaz de promover a viabilidade de uma infância sadia e bela, em que a ideia de robustez seria apresentada como padrão e referência de perfectibilidade. 


\section{PERCEPÇÃO DOS MÉDICOS ACERCA DO AUTISMO ENQUANTO ETIOLOGIA E CARACTERÍSTICAS}

Apesar de muitas controvérsias a respeito da etiologia do autismo, que vão da organogênese à psicogênese, na Psicanálise veem-se os aspectos psicomotor, cognitivo e de aquisição da língua, além de um efeito puramente maturacional. A partir desses, acredita-se na articulação deste real orgânico à tela simbólica parental, o que dá lugar às antecipações imaginárias e funcionais que os pais colocam em cena para um bebê (CAMPANÁRIO, 2008).

Assim, além de sintomas físicos, como dificuldades na alimentação, irritabilidade, atrasos no engatinhar, andar, sentar, dentre outros (idem), atenta-se à troca de olhares entre o bebê e a mãe, se ele busca ativamente o olhar da mãe, se responde a sua fala (manhês), ou seja, avalia-se a instauração do circuito pulsional, uma vez que se acredita que este não foi completado no autista (LAZNIK, 2004).

Ao serem questionados em relação à etiologia, os médicos entrevistados demonstraram dúvidas. Contudo, a maioria vê o autismo como um distúrbio orgânico: “...Origem genética... gêmeos monozigóticos, dificilmente os dois não vão ter traços de autismo... realmente a genética é bem forte...” (P 9); “Deve ser genético... Inclusive já ouvi qualquer coisa bem discutível, querendo atribuir um pouco na parte de espiritismo" (P 1).

Ainda não se sabe ao certo a etiologia do autismo. A Psicanálise aplicada a bebês não nega o fator orgânico ligado a este transtorno, mas acredita que seja algo além do componente genético, já que várias intervenções precoces mostram uma boa evolução em quadros com este risco. Além disso, independentemente da origem etiológica, é fato que o autismo traz consequências psíquicas. Assim, tal patologia deveria ser objeto de grande preocupação e interesse para os profissionais da primeira infância.

A pediatria é a medicina do desenvolvimento global, físico, intelectual e afetivo, cuja prática deve centrar-se não só no tratamento de crianças e adolescentes, mas, sobretudo, ajudá-los a se tornarem adultos sãos. Da mesma forma, espera-se que o pediatra assuma que cada consulta é uma ocasião para enxergar, tratar e orientar o sujeito em sua integralidade, porque, nesse momento, ele é também um educador em saúde pública (ANDRADE, 2005).

Frequentemente, os médicos dedicam seu olhar às patologias orgânicas, ou seja, ao que se pode curar, pois isso orienta sua prática desde o surgimento da Medicina. Desse modo, para eles, é muito difícil admitir que algo escapou aos seus conhecimentos, ou seja, o registro psíquico. Assim, preferem não olhar para o bebê e o seu sofrimento, para o qual acreditam não haver solução. Contudo, se eles pudessem compreender o quão essencial é este olhar para a constituição do bebê, dedicariam um pouco mais de seu tempo para supor, naquele peque- 
no corpo, um sujeito. Aliás, o olhar do médico sobre o bebê é essencial, pois é justamente esse que escapa ao autista.

Em relação aos sinais que caracterizam o autismo, Campanário (2008) aponta que, na primeira infância, eles são sutis, podendo apresentar, até mesmo, características opostas, como "bebês-modelo" que nunca choram ou "não incomodam", ou aqueles que demonstram não gostar de companhia, apresentam flacidez, rigidez ou irritação, reagindo a pequenos estímulos. Foster (1999) alerta para desconexões presentes desde oito ou nove meses de idade, quando o bebê apresenta pobreza ou ausência do reflexo de antecipação e aproximação oral ao peito materno, rechaço ao contato com o peito, pobreza ou ausência do reflexo de sucção, de fixação, de seguimento ocular e, posteriormente, do sorriso social.

Em geral, os médicos entrevistados reconhecem características autísticas somente em crianças depois dos dois anos de idade. Assim, não relacionam os problemas do bebê — como falta de controle esfincteriano, distúrbios do sono e alimentares, distonias musculares, etc. — ao risco de autismo. Possivelmente, é devido a esses fatores que os médicos entrevistados relacionam o autismo a características que surgem em crianças maiores, como a não afetividade ou a negação do olhar do outro: "Não tem muito aquela coisa de afetividade com as pessoas... não ter a troca... fazer coisas muito repetitivas... ter o prazer de brincar sozinha... personalidade um pouco antissocial digamos assim, né [sic]” (P 9).

Foster (1999) relata que as condutas de desconexão de tipo autista são frequentes na prática neuropediátrica e, por trazerem consequências graves para o desenvolvimento, é necessário que o profissional fique atento a elas. Contudo, muitas vezes, para Campanário e Pinto (2006), durante os primeiros anos de vida, os sinais indicativos de que algo não vai bem com a criança são pouco valorizados pelos clínicos.

Corroborando essa ideia, pode-se inferir que o risco de autismo não é percebido pela grande maioria dos entrevistados, que atentam mais para as falhas na comunicação e na interação. Estes profissionais não levam em consideração sinais mais sutis de risco nos bebês, (como evitação do olhar, hipotonias, entre outros), não os relacionam ao autismo ou não sabem o que fazer diante deles.

\section{DIAGNÓSTICO}

Bastante evidente nas entrevistas foi o encaminhamento dos pacientes, assim que se diagnosticou o autismo ou houve a sua confirmação. Essa questão fez surgir duas possibilidades em relação aos médicos entrevistados: alguns encaminham para neuropediatras, psiquiatras ou neurologistas, na tentativa de buscarem a confirmação daquilo que os desconforta; para outros, este encaminhamento é uma forma de não precisarem se comprometer com esses pacientes que os 
angustiam. Infelizmente, essa última hipótese parece ser a mais percebida nas "entrelinhas" do discurso dos profissionais. "Quando suspeito, eu encaminho para a neuropediatra" (P 10); "Encaminho sempre” (P 4).

Um aspecto bastante relevante foi o pequeno número de pacientes autistas atendidos pelos pediatras em comparação aos neuropediatras, o que leva a pensar que, uma vez diagnosticados, os autistas passam a ser acompanhados - mesmo devido a uma febre ou dor de garganta - pelos neuropediatras. É provável que as próprias famílias elejam para o acompanhamento de seus filhos os profissionais mais sensíveis, que se mostraram mais conhecedores do tema e com maior habilidade para lidar com os pacientes e suas famílias.

Stellin (2007) aponta que o pediatra é o profissional de referência da primeira infância; por isso, seu papel é fundamental na detecção dos sinais precoces de problemas no bebê. Inclusive, a possibilidade de leitura desses sinais é primordial no manejo de certas situações clínicas que permitem ao casal parental identificarse com o olhar do médico sobre seu bebê, reposicionar-se diante dele ou buscar encaminhamento para o tratamento psicanalítico. Além disso, para Bernardino (2008), quanto mais precoce for a detecção, mais cedo a criança terá a possibilidade de receber tratamento com seus pais, melhores serão os resultados e as chances de remissão do quadro.

No entanto, o que se vê na prática é que há grande dificuldade de se perceber o risco de autismo. Fala-se em percepção do risco porque, para a Psicanálise, o diagnóstico não é a prioridade, mas uma intervenção precoce a partir dos sinais clínicos. Mesmo assim, o diagnóstico faz parte da cultura da Medicina, e se percebeu que os médicos centram aí sua preocupação embora haja grande dificuldade para fazê-lo, como é possível perceber no seguinte relato: "Muitas vezes, a criança tem e não se sabe que tem, então, talvez seja bem por isso que se vê também menos, porque tem menos diagnóstico do que realmente existe (...) Esses dois já chegaram com diagnóstico. É bem mais fácil, né [sic], especifica, trata só o sintoma, então muitas medicações são usadas só para acalmar" (P 9).

Pode-se inferir que uma das maiores dificuldades em relação ao diagnóstico do médico seja o fato de que ele é guiado pelos aspectos clínicos, sobretudo se feitos a partir dos Indicadores Clínicos de Risco para o Desenvolvimento Infantil — Irdis (PESQUISA MULTICÊNTRICA..., 2005), os quais implicam aspectos comportamentais relacionados ao circuito pulsional. Assim, o fato de não haver exames que avaliem e mostrem as falhas que levam ao autismo parece ser angustiante para os médicos, pois estes percebem que o bebê não está bem, mas não veem marcas no corpo, ficando sem respostas que justifiquem o sofrimento da criança: "O diagnóstico em si é difícil de fazer porque é basicamente clínico, tu examina e não acha nada” (P 3). 
É fato que, para todo pediatra surgem casos em que sua competência falha. Além disso, são, a todo momento, convocados embaraços e desilusões, pois muitas vezes casos mórbidos e desagradáveis são alarmantes, mesmo quando os exames não apontam as causas. Assim, faz-se necessário que os médicos busquem, nos aportes teóricos psicanalíticos, em especial nos textos dedicados à infância, auxílio para suas dificuldades, possibilitando o diálogo entre a Medicina e a Psicanálise (NETTO, 2008).

Um dos neuropediatras trata do diagnóstico como uma intervenção: "A primeira intervenção é fazer o diagnóstico... existe uma dificuldade de fazer o diagnóstico, não é muito fácil” (NP 6). Contudo, um diagnóstico precipitado pode causar efeitos iatrogênicos, já que classifica, quando há apenas um risco. Assim, Laznik (2004) indica o cuidado que se deve ter com a iatrogenia, a partir do diagnóstico de um falso positivo, ou seja, a fabricação de uma doença que não existe. Deste modo, deve-se cuidar para não favorecer a angústia familiar sem necessidade. Meira (1998) argumenta que classificar uma criança como "autista" gera uma diferença significativa no discurso dos pais e produz, na criança, uma marca que a instala em uma rede em que o real toma conta do corpo, fraturando a possibilidade de uma inscrição simbólica.

Dessa maneira, muitas crianças têm suas vidas marcadas por classificações médicas que obstaculizam seu desenvolvimento, bem como o exercício que os pais possam vir a fazer de suas funções. Diante do diagnóstico que a criança recebe, os pais passam a buscar, no discurso científico, um saber que lhes diga como devem educar seus filhos, uma vez que eles os colocam no lugar que é atribuído ao "autista", consolidando uma posição que poderia ser apenas transitória (MEIRA, 1998).

Portanto, intervenção precoce não significa diagnóstico de autismo precoce, e isso parece estar confuso para a maioria dos médicos entrevistados. O que se espera dos profissionais é que tenham condições de perceber sinais de risco de transtornos do desenvolvimento infantil, como o autismo, e que trabalhem isso com os pais e o bebê na busca de reposicioná-los. Esta intervenção poderá possibilitar-lhes o (re)estabelecimento do circuito pulsional, em especial o terceiro tempo que se encontra ausente, para que o bebê possa oferecer-se ao Outro e fisgar seu gozo. Então, mostrar que há dificuldades no bebê, e até mesmo nos pais, não é o mesmo que dizer "seu bebê 'é' autista". Essa questão é apontada por um dos neuropediatras; todavia, sabe-se que dificilmente um bebê chegará ao seu consultório, a menos que haja outra patologia associada: "A criança pequena dá para a gente ver, só que assim oh [sic], tu não vai ser maluco de tocar nesse nome... tu levanta [sic] suspeita... aí o tempo vai passando e tu vê que a criança não está vindo, não está fazendo contato, não está desenvolvendo... certamente levantar os sinais dá, e o fardo vai ficando para ti” (NP 8). 
Logo, trabalhar com clínica de bebês é algo delicado e exige grande cuidado por parte dos profissionais, pois sua implicação é fundamental. O profissional envolvido, seja o médico, seja o psicólogo, não deve se precipitar em fechar um diagnóstico e fornecê-lo aos pais, porque lida com riscos, hipóteses. Certamente, não quer dizer que se deva omitir dos familiares que seu bebê não está bem, mas sim, trabalhar com eles a fim de que se deem conta dos sinais que a criança apresenta, bem como dar-lhes um espaço de escuta e de ressignificações para que haja um novo posicionamento do Outro diante do bebê que sofre.

\section{PROGNÓSTICO E TRATAMENTO}

Laznik (2004) ressalta que, mesmo em crianças autistas de três ou quatro anos, é possível (re) estabelecer o circuito pulsional completo. Contudo, o período mais sensível, quando a criança entra com naturalidade no campo dos significantes do Outro e pode deles se apropriar, já passou. Logo, é preciso trabalhar muito mais. Todavia, não há ainda uma comprovação fidedigna de que a propensão ao autismo, uma vez percebido seu risco, possa ser completamente revertida. O que se tem visto é que inúmeros casos evoluem de maneira favorável. De qualquer modo, mesmo que não se possa, até o momento, falar em remissão total dos sintomas, a significativa minimização dos danos já faz com que os estudos e trabalhos com bebês sejam válidos.

Dessa forma, um dos maiores problemas enfrentados no tratamento do autismo é o início muito tardio, ou seja, houve muitos anos de cristalização dos sintomas, mesmo que tenham sido constatados precocemente. O tratamento de autistas com mais de seis anos é bastante difícil, pois além de o contato com a criança ser mais limitado, é especialmente o próprio alcance do tratamento que ficará restrito ao seu objetivo terapêutico e não ao tempo maior que esse demanda (CAMPANÁRIO \& PINTO, 2006).

Os entrevistados salientam a falta de estrutura da cidade em que a pesquisa foi realizada, pois não há um lugar especializado, com atendimentos interdisciplinares, para receber pacientes autistas. Além disso, constatou-se também nas falas dos entrevistados que eles não percebem o tratamento do autismo como tendo prognóstico favorável, ou seja, não notam, em sua maioria, a evolução dos pacientes: "A gente sabe que é difícil... os pais falam que melhorou bastante, tu olha assim... e acha péssimo, e eles vêm bem feliz [sic] achando que melhorou horrores e então eles dizem que percebem algo, pequenos detalhes (...) É uma evolução que existe só que bem pequena dentro do que tu consideraria [sic] uma melhora a ponto de melhorar a qualidade de vida. Então, mas eu acho que sempre é valido só que quanto antes melhor” (P 9). 
Uma das neuropediatras entrevistadas, no início da entrevista, surpreende-se ao ver no consentimento livre e esclarecido que a pesquisa segue a abordagem psicanalítica, e depois relata: “Eu acho que tem que tentar é que ele siga a rotina, né [sic], o favorável é ele se adaptar à sociedade... almoço, jantar, banho... ter atitudes normais na rua, não correr, não ser agressivo, não entrar em pânico, eu acho que isso são os ganhos, né [sic], por isso que eu acho que o tratamento comportamental, eu vejo mais resultados, embora seja assim, mais radical, eu vejo mais resultados, porque a criança ela tem que ser ensinada" (NP 7).

Não se pode afirmar que apenas a psicanálise se propõe ao trabalho de intervenção precoce, nem se nega que o autista deva ter qualidade de vida, buscando, na medida do possível, a convivência em sociedade. Entretanto, o discurso médico e de algumas linhas teóricas parece priorizar a “reeducação” dos autistas. É nesse sentido que Bernardino (2008) afirma que as crianças com transtornos globais do desenvolvimento não conseguem encontrar uma significação para si, não entendem seu papel e seu lugar no mundo, não conseguindo estabelecer uma história de vida pessoal. Para esta autora, o trabalho na abordagem psicanalítica é o de construir, junto às crianças e seus pais, as possibilidades de significação, pois não há sentido para um ser humano em saber se trocar, escovar os dentes ou caminhar na rua, caso não entenda para que isso serve ou se não há uma razão para se levantar, arrumar-se ou comer corretamente — os rituais só têm valor na cultura quando se entende o seu porquê.

Nos relatos, nota-se também certo descrédito em relação ao tratamento que é dado aos pacientes autistas, descrito como frustrante e sem muitas possibilidades de evolução favorável: "O autismo é uma coisa em que a gente não tem muito o que fazer, né [sic], principalmente em matéria de medicações que é o que eu venho fazendo" (P 9).

Costuma-se pensar em múltiplos atendimentos especializados para o autismo. Foster (1999), porém, faz uma ressalva quanto a isso. O autor afirma que não é possível desmembrar o tratamento, sendo de extrema relevância o trabalho em equipe de um grupo interdisciplinar para que se possa encarar, com alguma possibilidade de melhora, uma patologia tão severa e frequente como o autismo. Por isso, a importância da interdisciplinaridade foi apontada pelos neuropediatras: "O ideal no meu entender seria que houvesse um grupo que vai atender a esse paciente, inclusive que se reunisse periodicamente para trocar ideias de como está evoluindo esse tratamento, o que cada um tá [sic] fazendo, o que cada um tá [sic] sentindo como avanço nesse tratamento, é importante” (NP 6).

Outros dois pediatras já se referem a uma intervenção mais precoce, atribuindo a isso a evolução mais favorável. O primeiro também aponta para a interdisciplinaridade: “Ter um trabalho com a família... o mais precoce possível, envolvendo os profissionais que forem, que se julguem necessários, mas sobre a 
coordenação de alguém, não pode ser cada um puxando para o seu lado” (P 2); “Não sei se é porque às vezes talvez o diagnóstico seja mais tardio... ou talvez não se tenha mesmo ainda um atendimento adequado e por isso, talvez não haja assim uma evolução boa” (P 5).

Campanário (2008) afirma que a clínica do autismo tem mostrado que a idade, no início do tratamento, é determinante de sua melhor evolução. Todavia, não apenas a idade nessa fase deve ser considerada para um bom prognóstico, mas também o tipo de tratamento, a frequência dos atendimentos, o modo como foi feito o diagnóstico dado aos pais e se havia suposição de sujeito por parte dos que estavam atendendo ao caso.

Apesar de haver muitos profissionais trabalhando com clínicas de bebês no Brasil, são raras as publicações que se referem ao número de crianças atendidas ou que sugerem a comprovação dos êxitos dos atendimentos. Provavelmente, isso ocorre pelo fato de a estimulação precoce ter surgido como especialidade clínica há trinta anos apenas (JERUSALINSKY, 2002) — inclusive, é nessa época que se inicia na França o trabalho com bebês desenvolvido por Laznik (2004), uma das precursoras desse campo.

\section{PERCEPÇÃO DOS SINAIS DE RISCO}

Para que se detectem sinais de risco psíquico no bebê, é necessário que o médico esteja atento e sensibilizado para tal. Entretanto, a pesquisa evidenciou que estes sinais de risco são percebidos tardiamente, ou porque se desconhecem quais sejam, ou porque há certa suspeita, mas se espera que, com o decorrer do tempo, a criança não os apresente mais. Um dos entrevistados, ao falar do DSM-IV, ressalta o compromisso dos médicos no acompanhamento do bebê: “...Essas alterações deverão estar presentes pelo menos em alguma dessas áreas antes dos três anos de idade... com relação ao bebê... se a gente fizer como tem que ser feito em cada consulta de puericultura de um bebê... consulta não é só para pesar e medir" (NP 6).

Na França, já se diagnosticam os perigos evolutivos entre três e quatro meses, pois nessa idade todas as crianças passam por um exame clínico obrigatório. Por isso, ensina-se aos pediatras a observarem atentamente a relação do bebê com seu Outro fundador, em geral, a mãe, já que os médicos têm uma formação que prioriza o desenvolvimento biológico e psicofísico e atentam mais às possibilidades motoras do bebê (LAZNIK, 2004).

Contudo, a realidade brasileira, sobretudo no que se refere à cidade pesquisada, é outra. As entrevistas apontam que os médicos não percebem sinais de risco de autismo, uma vez que não há o intuito de atentarem para os sinais psíquicos inadequados do bebê, nem os relacionam ao autismo: “A vó [sic] é pediatra e 
notou. Em casa ela dizia: ele é diferente, ele é diferente, ele é diferente e eu no consultório eu não achei nada, aí com o passar do tempo foi se caracterizando autismo... Eu não fui treinado para isso... certamente eu acho que se eu tivesse mais treinamento, mais tempo para isso, talvez eu percebesse" (P 10); "Pode passar por surdez, por alguma lesão cerebral, alguma paralisia cerebral, alguma coisa assim... Não é uma coisa que esteja sempre presente na cabeça da gente, então muitas pode [sic] passar" (P 5).

Pode-se perceber que não é dada atenção aos riscos do desenvolvimento há, inclusive, falta de conhecimento e de sensibilidade dos médicos em relação a esses sinais. Por isto, é necessária a capacitação dos médicos da primeira infância para que possam conhecer os Indicadores Clínicos para Risco Psíquico (Irdis) desenvolvidos pela Psicanálise (PESQUISA MULTICÊNTRICA..., 2005).

Parece não haver a preocupação de se investigar mais profundamente o desenvolvimento da criança, pois somente os aspectos mais visíveis são considerados. Entretanto, isso não quer dizer que tudo vá bem com o bebê: “A gente observa, mas muito pouco, porque a consulta é muito rápida, ela não é voltada para isso, né [sic], a consulta é sempre voltada para uma patologia clínica” (P 4).

$\mathrm{Na}$ verdade, durante os primeiros anos de vida, os sinais que indicam que algo não vai bem com o bebê são pouco percebidos ou valorizados pelos médicos. Assim, os pacientes passam por pediatras e especialistas, são submetidos a vários exames, mas só quando persiste o atraso na fala é que são encaminhados para tratamento em saúde mental (CAMPANÁRIO, 2006). Por isso, até que chegue ao consultório do psicólogo, a criança na posição autística passou por vários outros profissionais (fonoaudiólogo, fisioterapeuta, neurologista, entre outros), pois as primeiras hipóteses levantadas sobre o seu problema parecem sempre apontar para distúrbios físicos.

A ausência de percepção de riscos ou o diagnóstico tardio são relatados pelos neuropediatras, que recebem esses pacientes em seus consultórios somente depois dos dois anos de idade: "Que trazem aqui, em torno dessa idade, três anos, sempre aguardam que a linguagem venha. Às vezes os pais acham a criança... alguém acha e às vezes mais raramente o pediatra. Acho que a família e os vizinhos se dão conta primeiro, daí então eles vêm” (NP 7).

O mais intrigante nesse relato é que os pais ou outras pessoas percebem que algo não está bem com a criança, mas o médico não. Inclusive, nada é feito até que apareçam maiores déficits, como atraso na fala ou falta de interação social. Decerto isso acontece devido à credibilidade dos pais quanto ao saber médico, que dificulta suas percepções. Entretanto, isso é algo que foi construído historicamente, o que faz com os pais se calem.

No Brasil, vem aumentando o número de publicações e congressos sobre intervenção precoce em saúde mental. Há, ainda, uma pesquisa financiada pelo 
Ministério da Saúde, para se validarem os Indicadores Clínicos de Risco para o Desenvolvimento Infantil, desenvolvida a partir da interação do bebê com os pais e para uso dos pediatras. Assim, só se espera, a partir daí, a possibilidade de o médico perceber, cada vez mais cedo, as dificuldades na relação pais-bebês e suas consequências para a constituição psíquica da criança (BERNARDINO, 2008).

\section{CONCLUSÃO}

Nesta pesquisa caracterizou-se que, normalmente, os sinais de risco de autismo não são percebidos, o que leva a atrasos nos diagnósticos e, por consequência, a intervenções tardias, mas já haveria uma complexidade de sintomas que não apontam para um prognóstico favorável de desenvolvimento devido à cristalização dos sintomas deste transtorno. Diante disso, a Psicanálise propõe outra possibilidade: a intervenção precoce a partir da detecção de risco de autismo.

Portanto, o que se pode perceber é que a intervenção precoce não faz parte da realidade da cidade estudada, pois, em sua maioria, há grande desconhecimento dos médicos em relação à percepção dos sinais indicativos de risco para o autismo (distonias musculares, recusa do olhar, perturbações no sono, intolerâncias alimentares, entre outros), já que se detêm apenas nos menos sutis que aparecem mais tarde no desenvolvimento, como a ausência de linguagem. Contudo, a maioria dos participantes expõe a necessidade de uma formação adequada, dedicada à percepção mais precoce do risco de autismo. Isto é bastante animador, porque abre as portas para que a Psicanálise adentre os consultórios e trabalhe em conjunto com os médicos da primeira infância em prol dos bebês, especialmente na promoção da saúde mental.

Por certo, nada se pode garantir sobre o êxito no tratamento precoce de bebês. Contudo, muitos psicanalistas vêm trabalhando com clínica de bebês e percebem resultados favoráveis, porque os tratam tendo em mente a suposição de um sujeito ainda em vias de constituição, no qual há possibilidade de (re) estruturar o circuito pulsional que, no caso do autismo, não foi completado. Há intervenção na relação do bebê com as figuras parentais, sobretudo com o Outro primordial, para operar justamente na fratura dessa relação, ou seja, recolocar o laço funcional com o Outro. Assim, propõe-se uma intervenção quando falha a implementação do simbólico e o bebê não advém como sujeito, ficando preso ao puro real de seu corpo, devido a dificuldades suas anteriores ou dos pais.

Todavia, é preciso estar ciente que, se a intervenção precoce não for feita de maneira cuidadosa, pode causar iatrogenia, isto é, desenvolver uma patologia em que há risco, de acordo com a maneira que se comunica aos pais. Faz-se necessário, então, oferecer a essas crianças o espelho da cultura, atravessá-las com palavras e inscrever nelas um nome para além do diagnóstico a fim de não 
cair na alienação de uma rede de significações que se repete em torno de signos que não deslizam, não deixando outra escolha para elas que não seja seguir o automatismo do comportamento que se lhes atribui (MEIRA, 1998).

Deste modo, é preciso implicar-se nesse processo, instrumentalizar-se teoricamente, discutir com psicólogos e psicanalistas, além de buscar a articulação com os demais profissionais dedicados à infância, os pediatras em particular, pois é por seus consultórios que os bebês passam. Por isso, o trabalho deve começar com os médicos, e não com os bebês. Embora não se possa falar em prevenção para os problemas de ordem psíquica, pode-se, sim, falar em prevenir danos maiores no âmbito psíquico ou físico.

Assim, é primordial que os profissionais da saúde mental na infância, em especial os orientados pela psicanálise, possam dedicar-se ao trabalho com bebês. É preciso escutar os outros parentais, auxiliando-os a emprestarem suas significações ao bebê para seu surgimento, enquanto sujeito desejante, e divulgar esse trabalho, buscando parcerias com os demais profissionais. A partir disso, quem sabe será possível mudar a realidade e fazer com que os médicos da primeira infância possam ir além do encaminhamento e do diagnóstico, propondo-se a emprestar suas significações aos bebês em sofrimento e aos seus pais, mas principalmente, a olhar para os bebês, porque o olhar, para a Psicanálise, vai além da mera visualização de sintomas.

Recebido em 30/6/2010. Aprovado em 6/10/2010.

\section{REFERÊNCIAS}

ANDRADE, P. (2005) Pediatra generalista: hoje e o futuro. Revista de Pediatria do Ceará, 6 (1), 10-11.

BARDIN, L. (1977) Análise de conteúdo. Lisboa, Portugal: Edições 70.

BERNARDINO, L. (2008) "Aspectos psíquicos do desenvolvimento infantil”, in WANDERLEY, D. B. (Org.). O cravo e a rosa - a psicanálise e a pediatria: um diálogo possível? Salvador: Ágalma.

CAMPANÁRIO, I. (2006) “O atendimento psicanalítico do bebê com risco de autismo e de outras graves psicopatologias. Uma clínica da antecipação do sujeito." Dissertação de Mestrado, Faculdade de Filosofia e Ciências Humanas, Universidade Federal de Minas Gerais, Belo Horizonte, MG. 
CAMPANÁRIO, I. \& PINTO, J. (2006) O atendimento psicanalítico do bebê com risco de autismo e de outras graves psicopatologias. Uma clínica da antecipação do sujeito. Estilos da Clínica, 11 (21), 150-169.

(2008) Espelho, espelho meu: a psicanálise e o tratamento precoce do autismo e outras psicopatologias graves. Salvador: Ágalma.

CORREIA, J.R. (1997) "Por que uma intervenção precoce nos distúrbios psíquicos?”, in WANDERLEY, D.B. (Org.). Palavras em torno do berço. Salvador: Ágalma.

COSTA, J. (1999) Ordem médica e norma familiar (Rev. Ed.). Rio de Janeiro: Graal.

DEGENSZAJN, R. (2008) “Uma experiência de ensino de saúde mental da criança com médicos residentes de pediatria”, in WANDERLEY, D.B. (Org.) O cravo e a rosa - a psicanálise e a pediatria: um diálogo possível? Salvador: Ágalma.

FOSTER, O. (1999) “Autismo em neurologia infantil”, in JERUSALINSKY, A. (Org.), Psicanálise e desenvolvimento infantil: um enfoque transdisciplinar. Porto Alegre: Artes e Ofícios.

FRASER, M. \& GONDIM, S. (2004) Da fala do outro ao texto negociado: discussões sobre a entrevista na pesquisa qualitativa. Paidéia: Cadernos de Psicologia e Educação, 14 (28), 139-152.

INFANTE, D. (2000) "O Outro do bebê: as vicissitudes do tornar-se sujeito”, in ROHENKOHL, C.M.F. (Org.) A clínica com o bebê. São Paulo: Casa do Psicólogo.

JERUSALINSKY, J. (2002) Enquanto o futuro não vem. Salvador: Ágalma.

KUPFER, M. (2000) Notas sobre o diagnóstico diferencial da psicose e do autismo na infância. Psicologia USP, 11 (1), 85-105.

LAZNIK, M. (2004) A voz da sereia: o autismo e os impasses na constituição do sujeito. Salvador: Ágalma.

NETTO, J. (2008) “A psicanálise em clínica pediátrica”, in WANDERLEY, D.B. (Org.) O cravo e a rosa - a psicanálise e a pediatria: um diálogo possível? Salvador: Ágalma.

PEREIRA, J.S. (2006) "História da pediatria no Brasil de final do século XIX a meados do século XX.” Tese de doutorado, Faculdade de Filosofia e Ciências Humanas, Universidade Federal de Minas Gerais, Belo Horizonte, Minas Gerais.

PESQUISA MULTICÊNTRICA DE INDICADORES CLÍNICOS DE RISCO PARA O DESENVOLVIMENTO INFANTIL (2005) Anais, Colóquio Franco-Brasileiro sobre a clínica com bebês, Paris, 2005. Recuperado em: 1/10/2009, da SciELO (Scientific Electronic Library OnLine): http://www.proceedings.scielo.br/scielo.php?script=sci_art text\&pid =MSC0000000072005000100007\&lng =en\&nrm=iso

RICHARDSON, R. (1999) Pesquisa social: métodos e técnicas. São Paulo: Atlas.

STELLIN, R. (2007) Conexões entre pediatria e psicanálise: apresentação de uma proposta de interdisciplinaridade. Revista de Pediatria, 8(1), 48-52. 
WAJNTAL, M. (2000) "Diagnóstico precoce e constituição do aparelho psíquico”, in ROHENKOHL, C.M.F. (Org.) A clínica com o bebê. São Paulo: Casa do Psicólogo.

WANDERLEY, D. (2008) “Intervenção precoce nos transtornos psíquicos das crianças”, in WANDERLEY, D.B. (Org.) O cravo e a rosa - a psicanálise e a pediatria: um diálogo possível? Salvador: Ágalma.

ZANOLLI, M. \& MERHY, E. (2001) A pediatria social e as suas apostas reformistas. Caderno de Saúde Pública, 17 (4), 977-987.

Mariana Rodrigues Flores

mari.rflores@hotmail.com

Luciane Najar Smeha

lucianes@unifra.br 